\title{
A Review on Using Opportunities of Augmented Reality and Virtual Reality in Construction Project Management
}

DOI 10.2478/otmcj-2018-0012

Received May 30, 2018; accepted Nov 05, 2018

\begin{abstract}
Augmented reality (AR) and virtual reality (VR), a kingdom-of-the-art technology for superimposing information onto the real world, have recently started to have an effect on our everyday lives. In addition, AR and VR have shown a great contribution to advanced construction management in recent years. However, a comprehensive critical review of AR and VR technologies in construction management is absent in the literature. This study provides a comprehensive review of a summary of using potential opportunities of AR and VR to solve a variety of construction management issues effectively and efficiently. This study found that AR is successfully used in construction project scheduling, progress tracking, worker training, safety management, time and cost management, and quality and defects management. VR is effectively used as a visualization tool, worker training technology, safety management tool, and quality and defects management tool. In addition, AR and VR are used for developing a network that allows the possibility of having conferences with those who are geographically far off from each other or the construction site. This study could help to explore the potential fields of using AR and VR technologies in the construction industry effectively as advance time- and cost-saving profitable tools.
\end{abstract}

Keywords: Augmented Reality, Virtual Reality, Construction Industry, Construction Management, Advance Construction Technology

\footnotetext{
*Corresponding author: Shakil Ahmed, Dept. of Building Engineering and Construction Management, Khulna University of Engineering \& Technology, Khulna, Bangladesh, E-mail:

ashakilmondol@gmail.com
}

\section{Introduction}

Throughout the twentieth century and beyond, the world has seen huge modifications in extensive types and variety of aspects in the construction sector. In our regard, there has been a massive transformation and advancement within the construction industry all over the world. Through constructing larger and better things, the construction industry has revolutionized approaches, methods, techniques and strategies. Similarly, in order to overcome the shortage of fit workforce, long-time duration and defective work, the construction industry has taken advantage of technologies to better recruit and preserve new workers and methods in the construction profession (Escamilla and Ostadalimakhmalbaf 2016). One of the technological tools used by the construction industry is called virtual reality (VR), wherein a three-dimensional, computer-generated environment can be explored and interacted through a person. Augmented reality (AR) stocks the same concept, but in place of interacting in a nonexisting surrounding (digital fact), AR makes use of the existing environment at the same time as implementing virtual elements to appear as if both are together at the same time (Dunleavy and Dede 2014). AR is a kind of interactive, reality-based display environment that takes the capabilities of computer-generated display, sound, textual content and effects to enhance the user's real-world experience (Loijens et al.2017). AR combines real and computer-based scenes and images to deliver a unified but enhanced view of the world. The VR is the computer-generated simulation of a three-dimensional image or environment that may be interacted within an apparently real or physical manner by a person with the use of a special digital system, which includes a helmet with a display screen inside or gloves outfitted with sensors (Whyte 2003a).

A variety of applicability assessment of AR and VR in architecture, engineering and construction can be found in Dunston and Wang (2011), Li et al. (2018), Park et al. (2013), Sampaio et al. (2010) and Wang (2009). However, 
effective use of AR and VR is not easy in the construction sector; for this, many researchers had worked hard in the last few decades. The successful outcomes appeared in the recent years than previous attempts. There are various sectors in construction that show successful implementation of $\mathrm{AR}$ and VR as desired.

AR and VR technologies have many applications that could benefit a project with accelerated working site training and safety, design development and communication with involved parties from the owner all the way down to the laborer and help to exceed owner's expectations and decrease project costs (Behzadi 2016). AR and VR are being used in the world of construction engineering and management by placing a 3D model in the front of the eyes of the consumer, consultant and contractor and starting up a learning experience unlike any seen before (Park et al. 2013). In this way, it permits for an individual to interact with real-world projects and deal with defects, risks and accidents before they even occur. Through creating exposure to a project before it physically exists, AR and VR create a unique gaining knowledge of opportunity for the inexperienced and construction-savvy people alike by means of presenting the opportunity to locate and fix a project's flaws in a safe, hazard-free environment all in real time (Lin et al. 2013). AR and VR are the future of construction as they are used in various important parts of projects. Worker's safety training, defects management, quality management, projects scheduling, information collection, safety management, logistics management, project progress evaluation and so on are conducted by the AR and VR technologies in the modern construction process. As there is no summarized information of using opportunities of AR and VR in the construction management available in the open access literature. To fill the gap, this study could be valuable to the potential readers. So the objective of this study is to find out the effectiveness and application opportunities of AR and VR technologies in the construction management. This study summarizes the various researchers' efforts to use AR and VR in construction effectively than existing methods and models. This study could help the authorities to know and understand the usability and effectiveness of various AR and VR technologies to solve many managerial issues in the construction management.

\section{Research Method}

AR and VR technologies are extensively used in recent years for research purposes or experimentally in the construction project management. Different researchers get success in different sections of construction management such as quality management, safety management, planning and scheduling, defect identification, cost and time management and worker training. Hence, using opportunities and benefits of AR and VR in the construction management is spread out across the literature. To know and learn all the effective use of opportunities in various departments of construction management is very difficult without any summarized structured of information. In identifying the key research relating to the AR and VR technologies in the construction management, this paper provides a review in terms of various aspects.

As it is a literature review, for conducting this study, comprehensive literature review was conducted throughout the distinguish sources, such as journal papers, conference papers, newspapers, websites, blogs, books and electronic media, which related to AR and VR in the construction sector. Relevant publications were identified by searching the Web of Science, Google Scholar, ResearchGate, Scopus and ASCE Library databases with the following keywords:

(1) Research topic: "construction safety management", "quality and defect management", "time management", "cost management", "planning and scheduling of project", "worker training”, "visualization and inspection", "project progress tracking”, "progress assessment", "construction communication" and "information collection/sharing/exchange", "advanced construction management', "AR in construction" and "VR in construction".

(2) Construction management: "construction", "construction management”, "BIM”, “CAD”, "VR”, “AR”, "safety”, "quality”, “training”, "progress”, "QA/QC” and "technology".

(3) Research direction and field: 'science and technology”, “engineering management”, "construction management", "civil engineering and construction", "automation in construction", "building technology", "computer aided design in construction" and "quality, risk and safety".

The search words helped to identify 84 relevant papers in distributed sources. These are summarized in Figure 1 in terms of the number of annual publications from 1997 to 2018.

\section{AR in Construction}

AR is used in various phases and departments of construction project. Many researchers believe that for bringing the automation in construction, AR is the most and obvious 
12

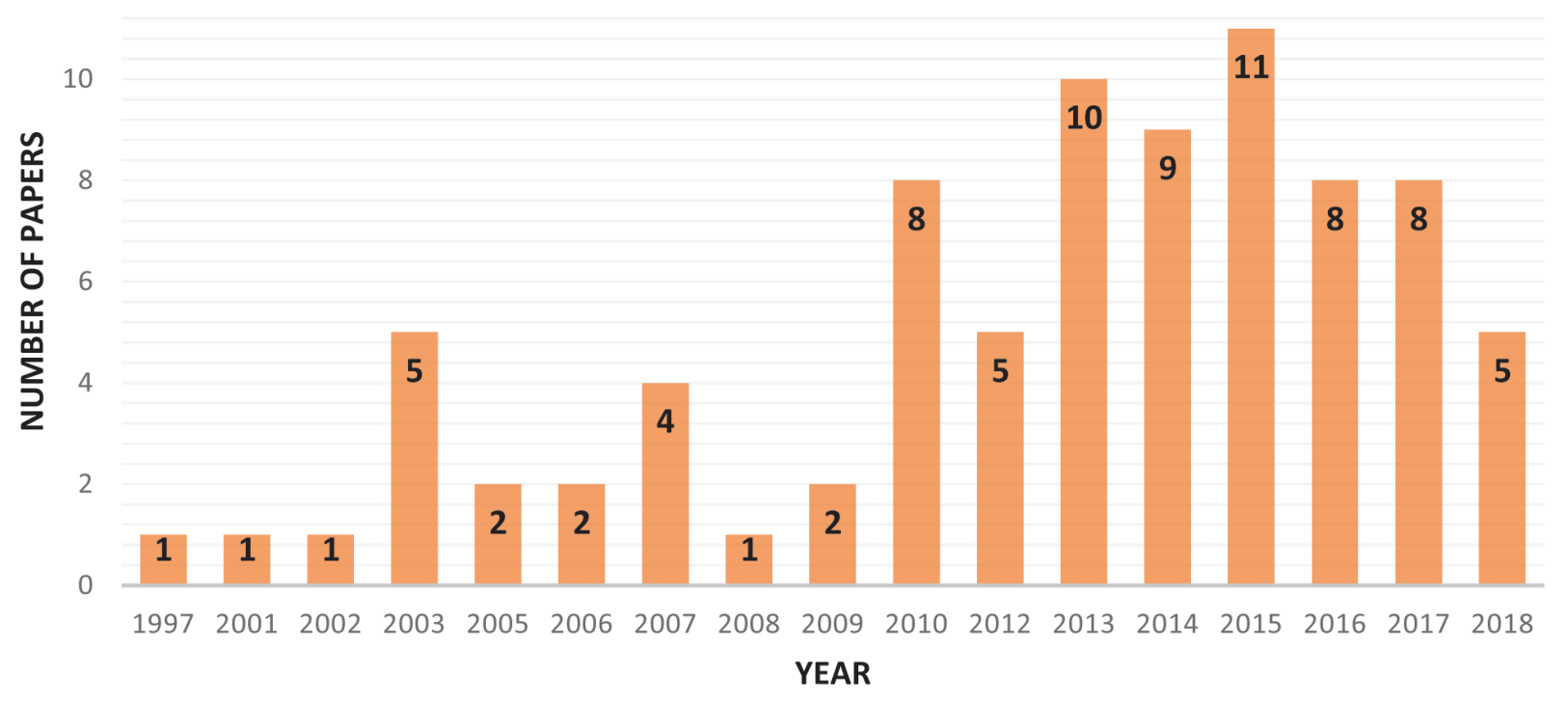

Fig. 1: Number of reviewed publications by year.

technology to implement in the construction project. In 2018, it is undoubtable that AR has a great contribution to change the culture of the construction industry to a fully automated sector in near future. In this section of the review, various using opportunities of AR technologies are discussed through analysis of numerous research articles.

\subsection{Scheduling and project progress tracking}

AR has enhanced the scheduling aspect of the construction project significantly; it is able to show an as-planned vs. an as-built form to allow visualization of progress. From the study of Zaher et al. (2018), Figure 2 shows the scheduling and progress tracking of the construction project by AR application. The white color portion of the model is completed, and green portion is behind the schedule of a residential construction project. Hence, the green portion actually represents the delay of project. Wang et al. (2014a) showed in their study that AR could be used as a scheduling tool better than other existing tools to understand and to make someone understand without any ambiguities. Chantawit et al. (2005) also used AR technologies effectively for the scheduling of project with visualization feature in early twenty-first century. Zaher et al. (2018) used the mobile AR technologies integrated with Microsoft Project and Primavera for construction project scheduling and schedule monitoring. Hui et al. (2017) showed in their research that AR could be effectively used for the safety task scheduling in a construction project.
These highlighted researches along with other researches have changed the definition of scheduling in the construction sector in recent years.

Meža et al. (2015) stated in their study that for monitoring and tracking the construction project, AR on tablet PC or mobile is the best option than other 3D models or Gantt chart. They also pointed out that AR has been able to represent that it is possible to visualize and estimate the work this is performed on site in accordance with the proposed schedule of the process. Wang et al. (Park et al. 2013) noted the use of AR for construction project progress tracking as a way to compare the project progress to the schedule. A visual comparison between the planned facilities versus as-built facilities is easily displayed by the AR technologies. Wang et al. (Park et al. 2013) also monitored a step in addition and connected AR to material tracking to make sure that the necessary materials are on site. Golparvar et al. (2009), Omar and Nehdi (2016), Zhou et al. (2008) and Turkan et al. (2012) also showed that in construction progress tracking and scheduling, AR is going to be one of the most used functions in advanced construction project management.

\subsection{Communication and data acquisition}

An important prerequisite to make successful construction project is underlying within the effective communication and information retrieval from the construction site. Pejoska et al. (2016) noted in their study that access 
to project information on-work site and effective communication are significantly enhancing with the introduction of different AR programs as compared to more traditional information sources. Figure 3 shows how the
AR technologies are used for the field data collection and distribution to the user in the construction industry. It also represents the communication ways between project participants and project information.

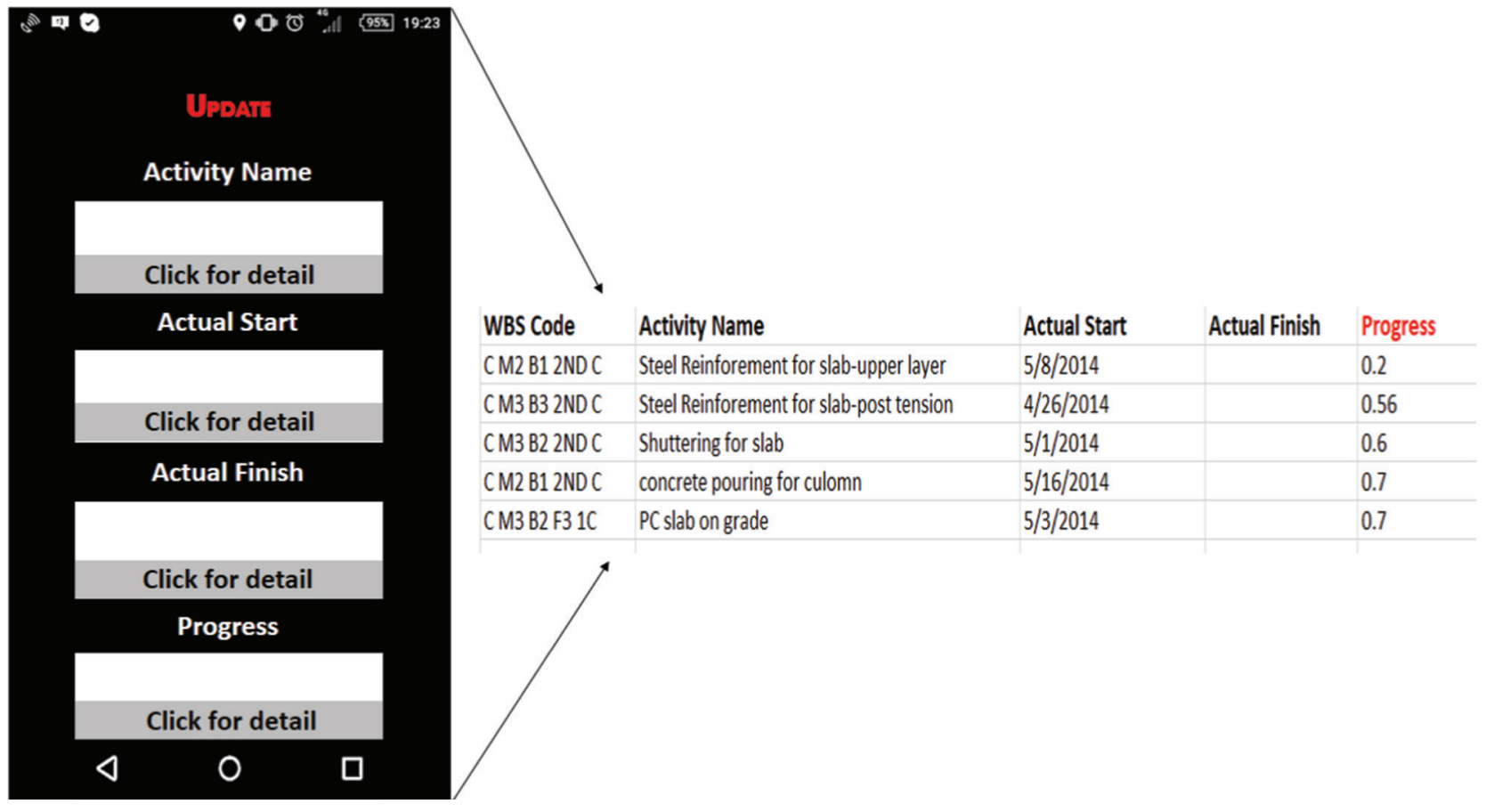

Fig. 2: Construction project scheduling and progress tracking by AR technology (Zaher et al. 2018).

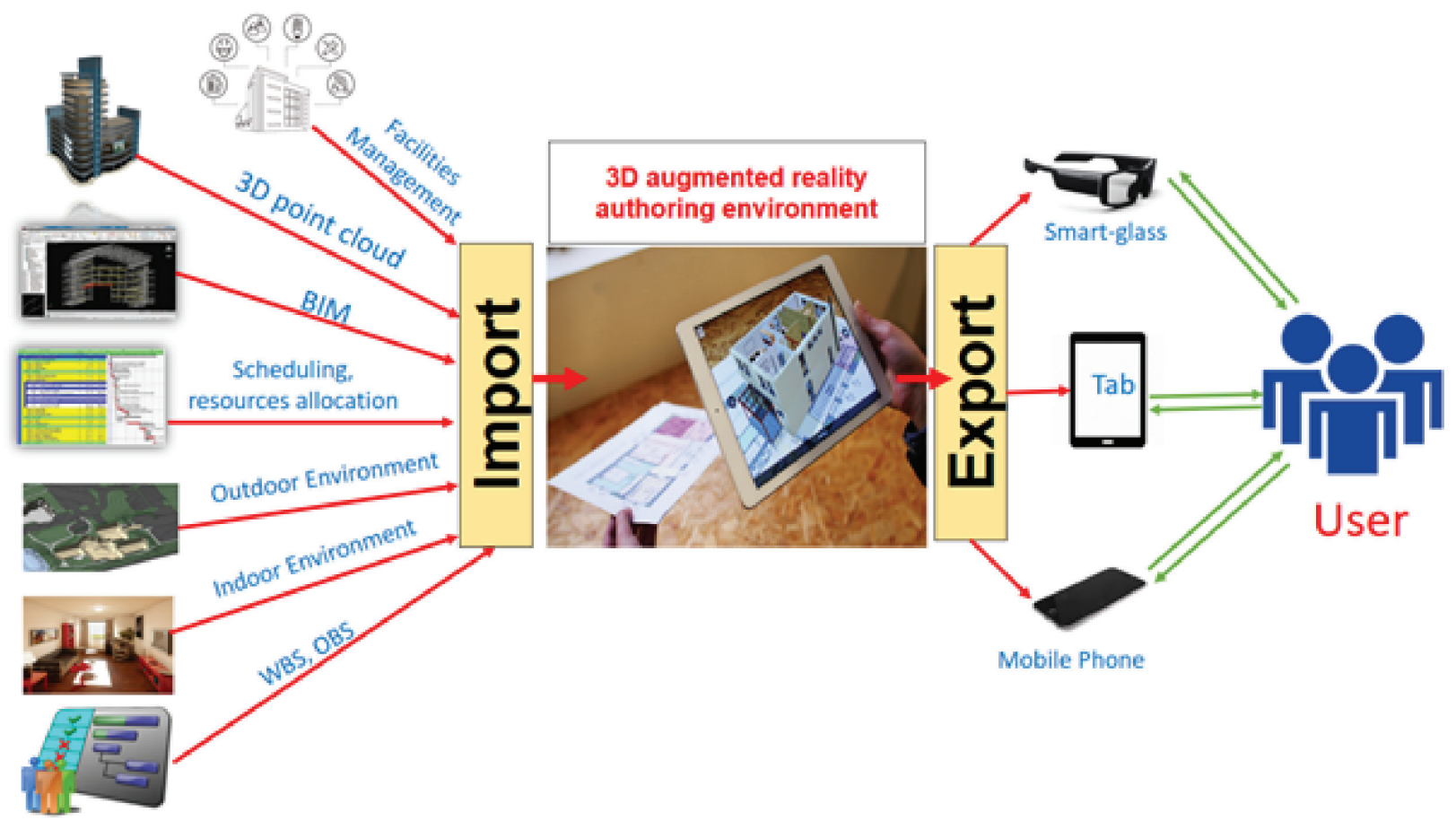

Fig. 3: Construction field data and design information acquisition process using AR technologies. 
AR systems allow fast and easy access to information and helps project managers to decide on corrective actions to minimize cost and delays due to performance incompatibilities (Bae et al. 2013). Yeh et al. (2012) stated that to reduce the difficulties and complexity for on-site data retrieval, many organizations are undertaking effort to develop light-weight mobile devices. The study also noted that organizations are working to develop devices that could exchange detail drawings and related information based on the location of the user. The added visualization benefits of AR technologies allow for better communication between parties when commenting and making suggestions for a particular project. The introduced visualization features and benefits of AR technologies allow for better communication between different parties involved in the construction project when commenting and making suggestions and decisions for a specific project (Behzadi 2016). Various researchers (Klopfer et al. 2002, Golparvar-Fard et al. 2009, Omar and Nehdi 2016, Reddy et al. 2010, Van Krevelen and Poelman 2010, Woodward et al. 2010) indicated in their study that AR is one of the most effective ways of collecting information from the construction site and could be a way of effective communication between different stakeholders of the project.

\subsection{Quality and defect management}

Quality management and defect control are important parts of construction management. There are many completed projects accepted by the client that are defected or failed to meet the desired quality and after arise disputes. To bring the automation in the quality and defect management system, AR plays a significant role in global construction. Various researches show the usability of AR in QA/QC in significant ways. As in Figure 4, Kwon et al. (Kwon et al. 2014) showed the process of marker-based AR technology for defects and quality management. Their study developed an effective tool for defect identification and correction. The whole construction period and maintenance period both could be facilitated by the AR technologies in the QA/QC sector.

AR technologies facilitate construction management to deal with defects that are probably unnoticed in the inspection process and save time to do so. Park et al (2013) noted that if managers realize the core control time points and measures for works to be checked proactively through the defect element ontology, then the worker's performance can be automatically checked at the appropriate time with BIM- and AR-applied inspection equipment without visiting the workplace. A marker-based AR technology is used for the quality improvement and defects management of construction project, and the output is very satisfactory (Kwon et al. 2014). The study (Kwon et al. 2014) concluded as the AR technologies enhance the current manual-based defect management to reduce site managers' workloads and prevent construction work defects proactively by utilizing BIM and AR technologies. AR was regarded as a way to carry exceptional additional value and experience of concreteness, particularly in close-to-target locations in which the shapes and volume of the planned buildings could be visualized (Olsson

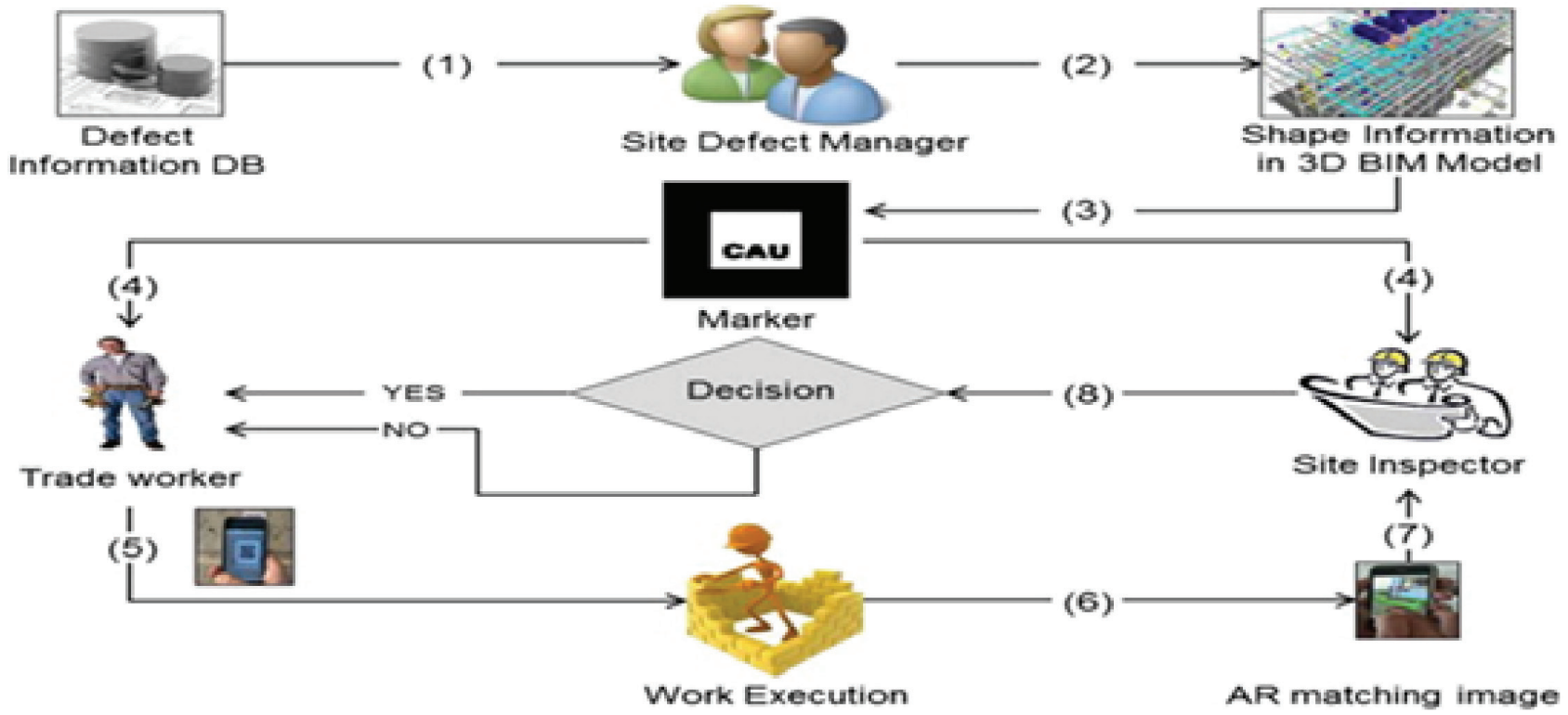

Fig. 4: Process of defect management by AR (Kwon et al. 2014). 
et al. 2012). An effective defectless facilities management system is developed for the construction project in a modern automated way that facilitates users at a more satisfactory level than any time before (Koch et al. 2014). AR is also mentioned as a fruitful quality and defects management technology for on-site construction project (Kim et al. 2013). To eliminate any defects in piping assembly in the construction project, an AR technology-based management system is developed and the system concluded with expected outcomes and showed hope for the future (Hou et al. 2013). Some others' studies (Bulearca and Tamarjan 2010; Lee et al. 2012; Rankohi and Waugh 2013; Williams et al. 2014) also show how the AR technologies are used in construction quality and defects management system.

\subsection{Time and cost management}

Time and cost are undoubtedly the major issues of construction process. All the management of construction project is to reduce the time of completion and save the expenses of the construction. Time and cost management of construction exists in the construction process from the beginning of construction history but is not significantly effective at any time. To increase the effectiveness of construction management, technological changing take place in different form with the changing in time. For the continuation of this changing, AR-based applications in construction management for monitoring and controlling the time and cost issues are appeared significantly.

Wong et al. (2014) stated that both time- and costsaving opportunities are available to the project managers by using AR technologies, which precise projects at the same time as lowering labor work/time and cost efficiencies because of defects and construction rework. About 9-13\% time and 14-19\% money are wasted because plans or drawings are misinterpreted or the information is transferred imprecisely from the plan to the real object (Kumaran et al. 2007). The AR technologies unravel issues including lack of manpower inside the management and costefficiencies in the construction project (Behzadi 2016). Park et al. (2013) and Kwon et al. (2014) showed in their study that for the defects and quality management, there is no more physical labor necessary to conducting defects management process. Physical inspection and reporting are very time consuming in the construction sector (Fan et al. 2015). So the manpower is reduced along with their associated cost and time of conducting these management processes. For the construction site's data acquisition, AR technologies are used effectively with saving time, reducing labor hours and decreasing data acquisition cost in most significant ways (Golparvar-Fard et al. 2009). The AR technologies reduce the defects and rework of the construction project; this means, they save time and cost of the construction project by using AR mobile computing technologies (Kim et al. 2013). There are some other studies (Azhar et al. 2015; Tang et al. 2003; Van Krevelen and Poelman 2010; Wang et al. 2014b) that have explored the opportunity of saving cost and reducing time of the construction industry by using AR technologies.

\subsection{Employee training and safety management program}

Safety management system is a very concerning issue in modern days in the construction industry. Thousands of people die every year in the world in construction accidents. The training of employees is another most important thing for every construction project. These issues are not easy at all to perform at the desired or standard level. However, AR technologies assist both issues to give the employees an effective training and implement the safety management system as the specification. Figures 5 and 6 show the AR-based safety management tools. Figure 5 is from HSE International (2017) who invented a wearable augmented glass for construction safety. In Figure 6, "ProVis AR”, a safety management AR-based learning mobile app, is used to train about crane safety.

Chi et al. (2013) showed in their study that AR technologies could be effectively used for the training of operators of heavy equipment in the construction projects. Wang and Dunston (2007) also revealed that AR technologies are significantly used for training construction workers to operate heavy and medium construction crane, excavator and assembling equipment. AR technologies assist the workers and stakeholders to understand various complex designs and arrangements in an easy and effective way and educate the project-involved persons about various project issues (Lee 2012). Izkara et al. (2007) developed a conceptual diagram of AR system for the safety at work site in the construction industry. For safety concerns, construction workers need to have and maintain a completely clear understanding of the real objects and safety hazards around them and the AR technologies assist the workers effectively to clear understanding (Stricker et al. 2001). Wang et al. (2013) developed a conceptual framework for integrating building information modeling with AR for the safety management system in the construction industry. So AR technologies are the new approach for the modern construction management, particularly in the training and safety management system. 


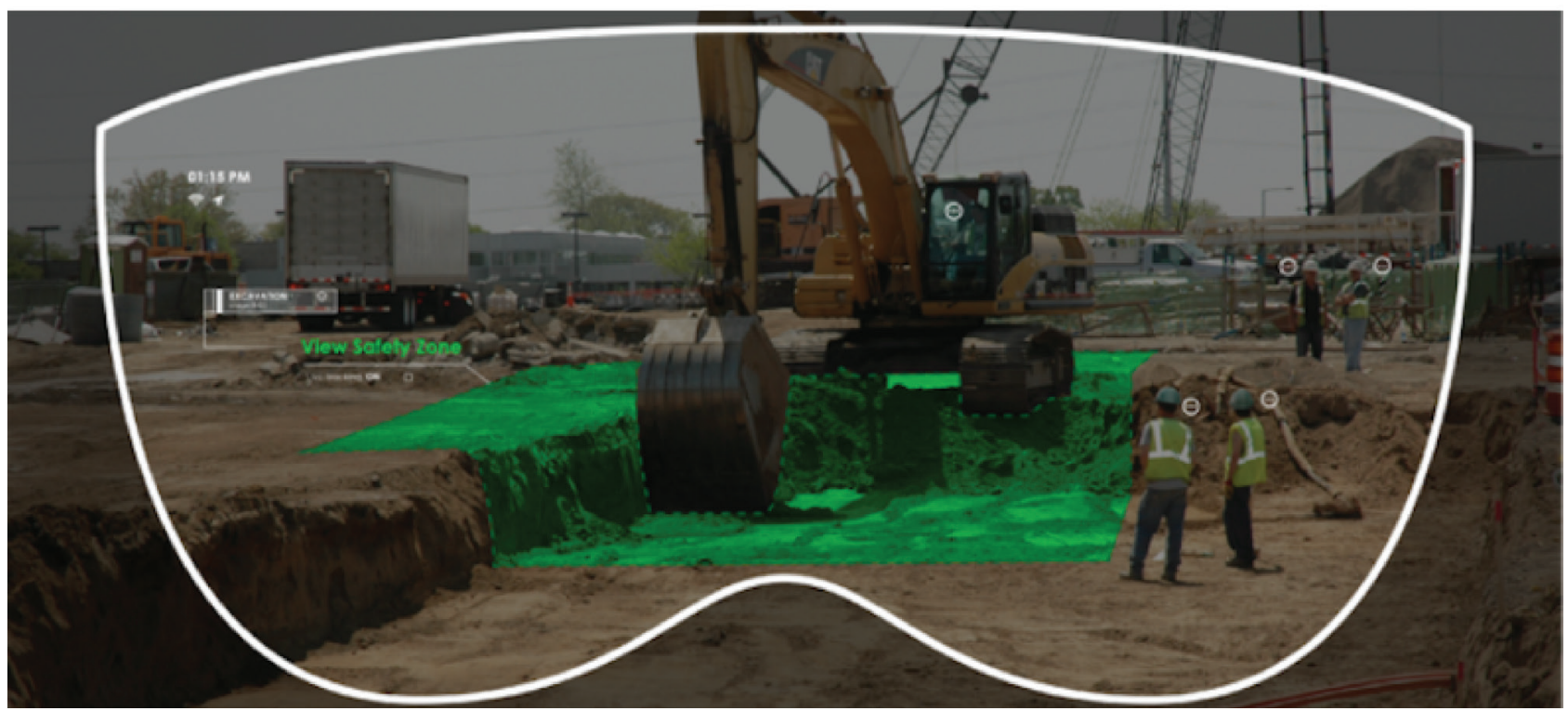

Fig. 5: AR-based wearable glass for construction safety (HSE International 2017).

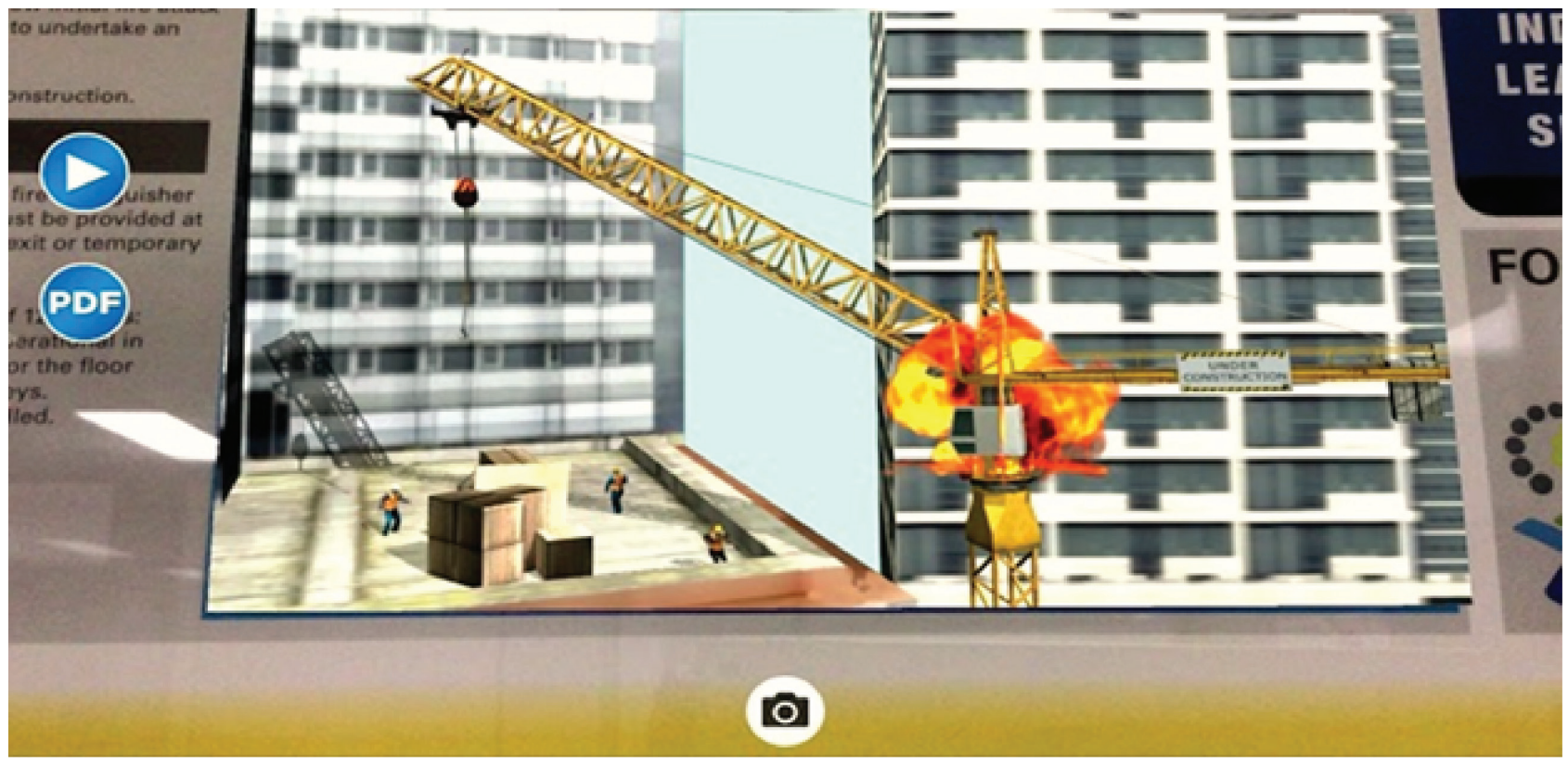

Fig. 6: AR-based construction crane safety application (Pro-Vis AR mobile app).

\section{VR in Construction}

Human beings are immersed in a new dimension with the feeling of the real world by the VR technologies. The noticeable fact about VR technologies is that they furnish the opportunity to get thrown into a new dimension with a new depth of digitally constructed reality that resembles real life. In the construction industry, dealing with the reality of workers and consultants, construction projects often failed for arising problems directly related with incapability, unreachability and inexperience of field personnel and consultants. In this case, VR technologies allow them to truly experience a project before it is built. VR technologies are now used in an integrated department of the construction industry. It is used as an essential tool for worker training, safety management system, progress tracking, labor management, defects management and so on. In this section of the review, comprehensive use of opportunities and benefits of these technologies is discussed through various research work analyses. 


\subsection{Worker training}

Before starting any project, there is no other concern in construction projects as important as workers' training is. The construction quality and safety of workers mostly depend on the proper training of the workers (Demirkesen and Arditi 2015; Rumane 2016). A construction project can gain more profit with excellent success if the workers of this project are highly trained in an effective manner (Kerzner and Kerzner 2017). The traditional construction training program is not significantly effective because workers do not understand the work and procedures and also do not know about the associated risks and hazards. Figure 7 (Knutt 2017) shows that a worker gets training for operating heavy construction excavator by VR technologies. This app is developed by a software company 3D Repo. This VR safety training system has been adopted by Cape, a contractor and supplier to the offshore and energy industries.

VR technologies are used for the worker training for the safety issue in the construction project (Le et al. 2015b; Park et al. 2015). For operating the crane, excavator and other construction equipment, VR-based training program is an effective and proven technology (Fang et al. 2014; Hilfert et al. 2016) in recent years. Peters et al. (2016) revealed that by providing VR-based training, it is possible to enhance the working ability of workers in particular construction work. Le et al. (2015a) developed a platform for training the workers who are assigned to steel erection activities in construction, and its outcome is significantly good. Zhao and Lucas (2015) proposed a framework for a VR training tool for design and installation of electrical systems in the construction project. Alcinia et al. (Sampaio and Martins 2014) developed some models that are used in an e-learning platform and assist professional training for construction field personnel and involved parties. Many researchers believe that VR technologies are undoubtedly effective training tools for the global construction industry in the modern age.

\subsection{Construction safety management}

Construction industry is considered as one of the most hazardous industries for it unique nature of risk and uncertainty. Safety needs to be the top priority to each person

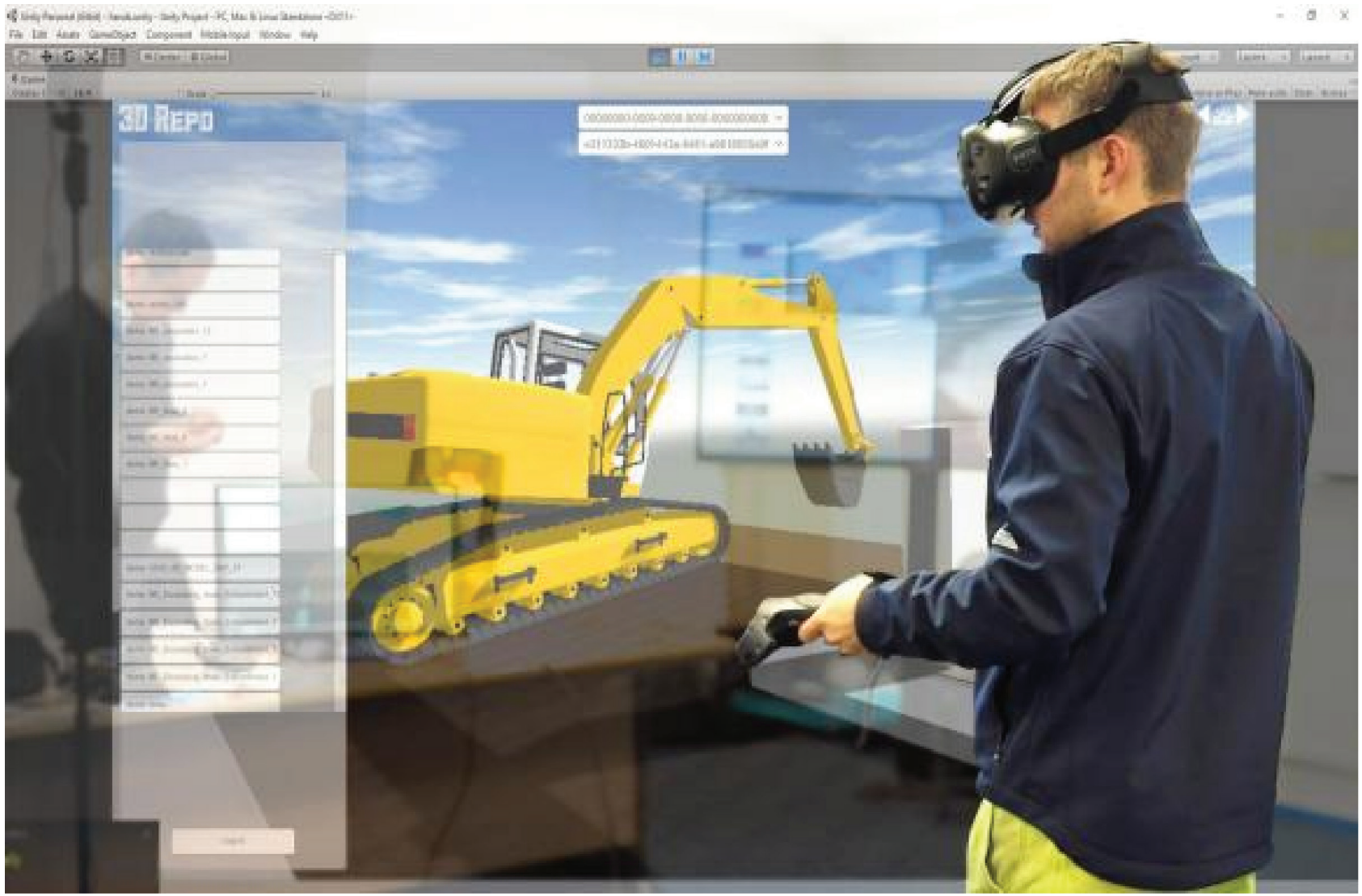

Fig. 7: Construction excavator operating training by VR technology (Knutt 2017) 
associated with our field of work in the construction project. Every year thousands of people die due to construction accidents (Rozenfeld et al. 2010). For the reduction in the accident rate in the construction site, VR technologies open wide windows for training, monitoring and controlling safety management of construction companies. The construction industry is a complex environment where excessive accident rates make widespread contributions to cost overruns and schedule delays. VR technologies could be playing an important role to provide safety training, education, warning, information and a learning platform for safety management in the construction industry. Figure 8 represents the opportunity of worker training on health safety issues through the VR technology. This app is created by 3M Science (Science 2017) for Personal Protective Equipment (PPE) training of worker.

Safety education is essential in promoting a safe and healthy working environment in construction. For this, Le at al. (2015b) developed a VR-based construction safety education system for experiential learning. Zhao and Lucas (2015) described a framework for construction safety management and worker training for safety performance by the help of VR tools. Bhoir and Esmaeili (2015) used the VR technologies in the construction safety management program, and they significantly reduced the rate of accident in a result. Sacks et al. (2015) showed that VR technologies are highly beneficial for designers to appreciate the implications of designs on the safety program. These applications of VR could run numerous drills or unique scenarios that will provide the user with a reallife feeling of a potential threat. Numerous authors also have a notion that tracking progress is not systematically monitored properly, making work sites at risk of potential dangers (Golparvar-Fard et al. 2015). A distinctive method for the use of augmented and virtual realities is how they could improve safety by acquiring better training and

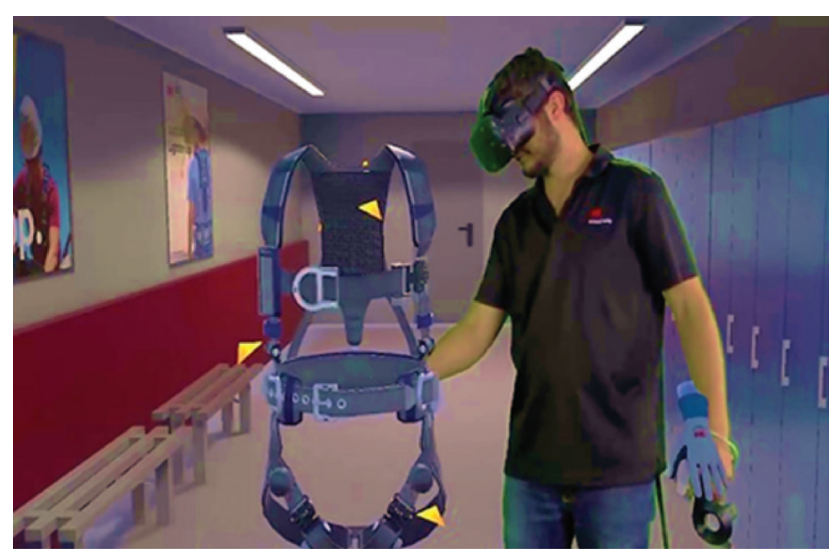

Fig. 8: Worker training on PPE by VR technology (Science 2017). education. A research illustrates, as an instance, how the use of AR proves the excellent training within the shortest time while also preserving the longest knowledge and skill acquired through the simulator (Sekizuka et al. 2017). There are some other researches (Chittaro et al. 2018; Guo et al. 2017; Hilfert and König 2016; Li 2018; Li et al. 2018; Sidani et al. 2018) who showed that various VR models, platforms and applications could be used effectively on construction safety issues.

\subsection{Defect and quality management}

Before the VR technologies in construction, the defect management system was a costly and time-consuming issue. Sometimes, the defect is overlooked and report is missed or damaged. However, with the help of VR technologies, defect management becomes very easy and effective. Here, there are no chances of overlooking and reporting damages. No physical labor needs to proceed with this operation. So labor, cost and time are saved by this method of the defect and quality management. Shen et al. (2010) showed how the VR technologies are used in the construction defect management in an effective manner than before. Dong et al. (2006) developed an application for construction defect reporting using VR-based mobile and digital workbench technologies from work site to head office without any time and workforce loss. Gordon et al. (2003) illustrated an automatic quality and defect management model using VR and used it in construction project positively. Wong et al. (2014) used VR technologies to develop a framework for proactive construction defect management with BIM technologies.

\subsection{Visualization}

Some decades ago, developing a construction project model virtually before staring the actual project was a nightmare. But today, by using VR technologies, a virtual project model is possible to build that give the feeling of real-world affection before the project started physically. Visualization of project model contains various parametric information that is not possible before or 2D CAD model. It works as a one-stop information booth and solution for all departments of the whole construction team. VR technologies allow a person to visit the whole project at its entire inside and outside peripheries with the new dimension of real-world feeling. VR is used in the planning phase for making effective decision with the demand of time. It also assists the consultant and contractor to design a project 
with available constructability. After the construction period, VR technologies reduce the effort and cost associated with maintenance and facilities management. Figure 9 shows a construction project model before the work is started. The image is collected from a developed VR-based visualization model of a study (Hilfert and König 2016).

A huge number of studies have been conducted on construction visualization using VR technologies over mostly the last three decades. Park and Kim (2013) used an application of VR-based technologies to visualize the hazards and risk of construction process. With the recent rapid advancement of visualization technologies, recognized research work for improving construction safety management practices has been conducted for identifying safety risks and worker on-site training by VR (Park and Kim 2013). Field construction can be planned, monitored and controlled more effectively by the detailed visualization using VR technologies (Kamat et al. 2010). Bouchlaghem et al. (2005) showed the advantages of construction project visualization using VR. Applications of VR provided an interactive, spatial, real-time medium for visualization of the project model that promotes safety, quality and defectless construction project (Whyte 2003b). There are some other studies (Cheng and Teizer 2013; Huang et al. 2007; Jayaram et al. 1997; Kopp et al. 2003; Shen et al. 2010; Woodward et al. 2010) that described the benefits of VR technologies for visualization of construction project at the planning, design, construction and maintenance period.

\section{Discussion}

It is clear from the recent researches that AR and VR technologies are the future of automotive construction management. Now, most of the construction management tools are integrating with AR or VR for increasing the output rate. Huge use of opportunities of AR and VR in the construction management is pointed out earlier. AR is used in project scheduling and project progress tracking in the modern construction process. However, the effectiveness of progress tracking is very significant than scheduling for both AR and VR technologies. For the effective and less time-consuming communication between different project participants, AR and VR are proven technologies. AR and VR provide a great platform for the project participants to share and exchange valuable information without any physical medium and within a second. AR and VR are also used for quality and defects management in the construction project. For the management of QA/QC, AR is greatly appreciated by the researchers than VR, but both play very important and effective role individually. The effectiveness of AR and VR technologies in quality management

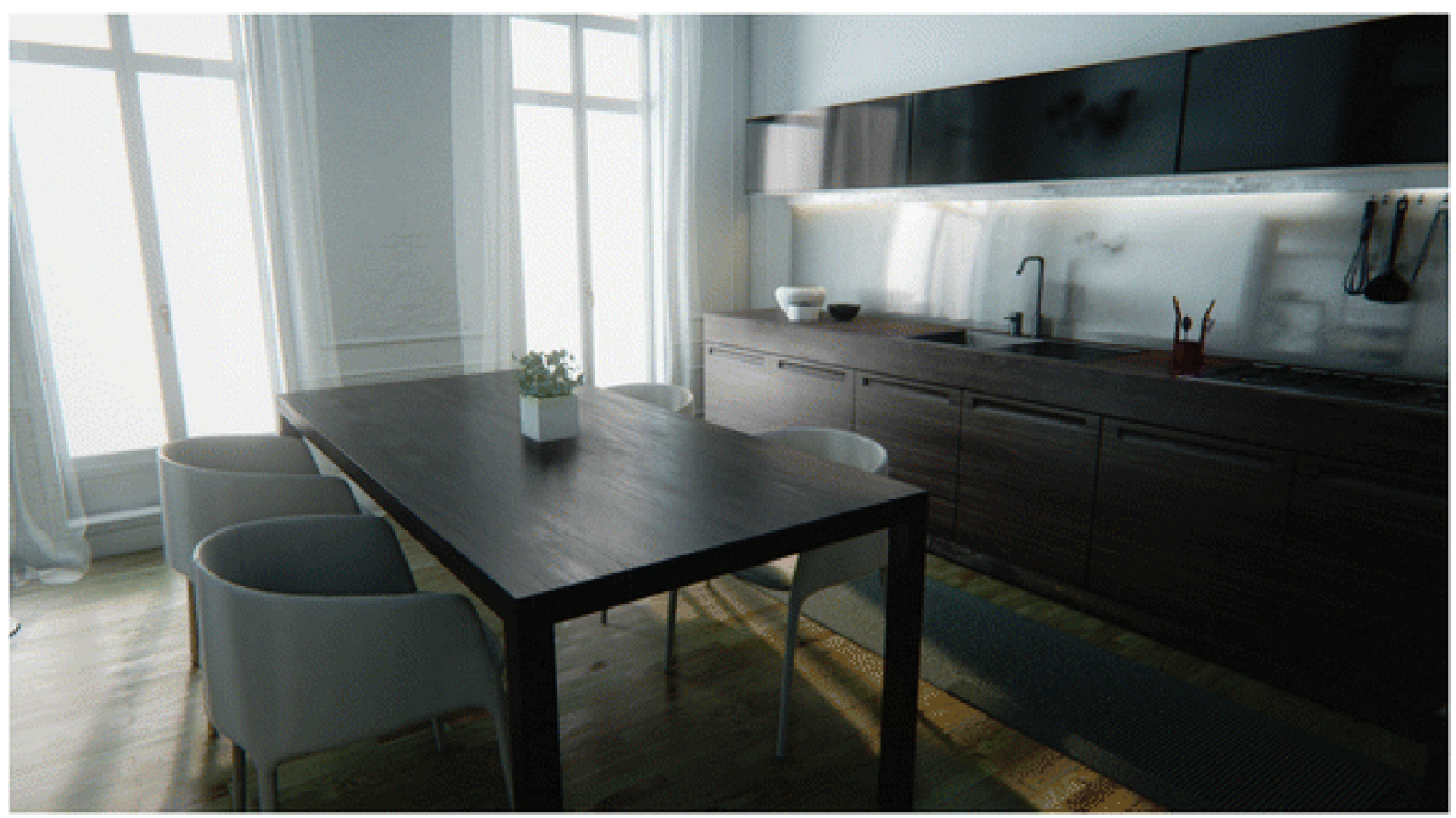

Fig. 9: Project model visualization before the actual work start (Hilfert and König 2016). 
is recommendable for every construction project. AR and VR technologies are hugely used in construction safety management and worker training for years. Many related researches proved that in training and safety management, AR and VR are the most effective and efficient tools in recent years. Project parametric model visualization and walk through into the project before the starting of the actual project with the feeling of the real world is another great characteristic of AR and VR technologies. For the visualization purpose, VR has a great contribution to the construction project from planning phase to maintenance phase. VR and AR are already used in many construction companies effectively, and many are preparing to adopt these technologies to visualization, training, safety and progress tracking of projects. Even though AR and VR technologies seem to be a vital tool in the construction industry, there are multiple drawbacks of these technologies too. There are some limitations and drawbacks that appeared to implement the AR and VR technologies in the construction industry. The high cost of AR and VR technologies, lack of AR and VR experts and technicians, unavailability of these technologies and maintenance are the major limitations for any construction company to adopt AR- and VR-based construction management system. Many researchers believe that all the drawbacks and limitations will be quickly broken by the upcoming generations. Assuming that AR and VR technologies will improve with safety, quality, visualization, workforce management and time management, it is far nearly sure that such technologies will play more important roles in construction for future years. Readers and respective authorities could use the AR and VR technologies to their construction projects to get maximum benefits of modern construction management and also work with constraints or limitations to overcome achieving ultimate profit by using AR and VR technologies in construction projects.

\section{Conclusion}

Construction industry is one of the largest industries in the world. Tremendous changes are going on from the beginning of the history of construction industry. Among the so many changes, the AR and VR technologies are bringing out an unimaginable modification and advancement in various construction management issues. The principal purpose of this study is to explore the using opportunities of AR and VR technologies in construction management and also explore the contribution to overcome various construction management issues from last three decades.
It is revealed in the study that these incredible improvements in AR and VR technologies are having a great impact on the construction industry in a couple of ways. In this review, various uses of VR and AR technologies are shown. This study discusses opportunities and associated benefits of using AR and VR technologies in construction management issues. It could be helpful to the potential readers to know the potential fields of using AR and VR in construction management aspects and learn how projects have been benefited by these technologies.

\section{References}

Azhar, S., Khalfan, M., \& Maqsood, T. (2015). Building information modelling (BIM): Now and beyond. Construction Economics and Building, 12(4), pp. 15-28.

Bae, H., Golparvar-Fard, M., \& White, J. (2013). High-precision vision-based mobile augmented reality system for context-aware architectural, engineering, construction and facility management (AEC/FM) applications. Visualization in Engineering, 1(1), p. 3.

Behzadi, A. (2016). Using augmented and virtual reality technology in the construction industry. American Journal of Engineering Research, 5(12), pp. 350-353.

Bhoir, S., \& Esmaeili, B. (2015). State-of-the-art review of virtual reality environment applications in construction safety. In: AEI 2015, Milwaukee, WI, March 24-27, pp. 457-468.

Bouchlaghem, D., Shang, H., Whyte, J., \& Ganah, A. (2005). Visualisation in architecture, engineering and construction (AEC). Automation in Construction, 14(3), pp. 287-295.

Bulearca, M., \& Tamarjan, D. (2010). Augmented reality: A sustainable marketing tool. Global Business and Management Research: An International Journal, 2(2), pp. 237-252.

Chantawit, D., Hadikusumo, B. H., Charoenngam, C., \& Rowlinson, S. (2005). 4DCAD-Safety: Visualizing project scheduling and safety planning. Construction Innovation, 5(2), pp. 99-114.

Cheng, T., \& Teizer, J. (2013). Real-time resource location data collection and visualization technology for construction safety and activity monitoring applications. Automation in Construction, 34, pp. 3-15.

Chi, H.-L., Kang, S.-C., \& Wang, X. (2013). Research trends and opportunities of augmented reality applications in architecture, engineering, and construction. Automation in Construction, 33, pp. 116-122.

Chittaro, L., Corbett, C. L., McLean, G., \& Zangrando, N. (2018). Safety knowledge transfer through mobile virtual reality: $\mathrm{A}$ study of aviation life preserver donning. Safety Science, 102, pp. 159-168.

Demirkesen, S., \& Arditi, D. (2015). Construction safety personnel's perceptions of safety training practices. International Journal of Project Management, 33(5), pp. 1160-1169.

Dong, A., Maher, M. L., \& Daruwala, Y. (2006). Construction defect reporting using mobile and digital workbench technologies. Available at https://digitalcollections.qut.edu.au/1661/.

Dunleavy, M., \& Dede, C. (2014). Augmented reality teaching and learning. In: Spector, J., Merrill, M., Elen, J., \& Bishop, M. 
(eds.), Handbook of Research on Educational Communications and Technology. Springer, New York, NY, pp. 735-745.

Dunston, P. S., \& Wang, X. (2011). An iterative methodology for mapping mixed reality technologies to AEC operations. Journal of Information Technology in Construction (ITcon), 16(30), pp. 509-528.

Escamilla, E., \& Ostadalimakhmalbaf, M. (2016). Capacity building for sustainable workforce in the construction industry. The Professional Constructor, 41(1), pp. 51-71.

Fan, C., Xiao, F., \& Yan, C. (2015). A framework for knowledge discovery in massive building automation data and its application in building diagnostics. Automation in Construction, 50, pp. 81-90.

Fang, Y., Teizer, J., \& Marks, E. (2014). A framework for developing an as-built virtual environment to advance training of crane operators. In: Paper presented at the Construction Research Congress 2014: Construction in a Global Network, Atlanta, GA, 19-21 May 2014.

Golparvar-Fard, M., Peña-Mora, F., \& Savarese, S. (2009). D4AR-a 4-dimensional augmented reality model for automating construction progress monitoring data collection, processing and communication. Journal of Information Technology in Construction, 14(13), pp. 129-153.

Golparvar-Fard, M., Peña-Mora, F. A., \& Savarese, S. (2015). Four-dimensional augmented reality models for interactive visualization and automated construction progress monitoring: Google Patents.

Gordon, C., Boukamp, F., Huber, D., Latimer, E., Park, K., \& Akinci, B. (2003). Combining reality capture technologies for construction defect detection: A case study. In: Paper presented at the EIA9: E-Activities and Intelligent Support in Design and the Built Environment, 9th EuropIA International Conference, October, 2003, pp. 99-108.

Guo, H., Yu, Y., \& Skitmore, M. (2017). Visualization technology-based construction safety management: A review. Automation in Construction, 73, pp. 135-144.

Hilfert, T., \& König, M. (2016). Low-cost virtual reality environment for engineering and construction. Visualization in Engineering, 4(1), p. 2.

Hilfert, T., Teizer, J., \& König, M. (2016). First person virtual reality for evaluation and learning of construction site safety. In: Paper presented at the ISARC. Proceedings of the International Symposium on Automation and Robotics in Construction, Auburn, United States.

Hou, L., Wang, X., \& Truijens, M. (2013). Using augmented reality to facilitate piping assembly: An experiment-based evaluation. Journal of Computing in Civil Engineering, 29(1), p. 05014007.

HSE International. (2017). Government initiatives grant for virtual and augmented reality development (AWE) in construction. Available at https://hseinternational.co.uk/ government-initiative-grants-1m-virtual-augmented-realitydevelopment-awe-construction/ Retrieved 23 May, 2017.

Huang, T., Kong, C., Guo, H. L., Baldwin, A., \& Li, H. (2007). A virtual prototyping system for simulating construction processes. Automation in Construction, 16(5), pp. 576-585.

Hui, P., Wei, J., \& Peylo, C. (2017). System and method for mobile augmented reality task scheduling: Google Patents.

Izkara, J. L., Pérez, J., Basogain, X., \& Borro, D. (2007). Mobile augmented reality, an advanced tool for the construction sector. In: Paper presented at the Proceedings of the 24th W78 Conference, Maribor, Slovenia.

Jayaram, S., Connacher, H. I., \& Lyons, K. W. (1997). Virtual assembly using virtual reality techniques. Computer-Aided Design, 29(8), pp. 575-584.

Kamat, V. R., Martinez, J. C., Fischer, M., Golparvar-Fard, M., Peña-Mora, F., \& Savarese, S. (2010). Research in visualization techniques for field construction. Journal of Construction Engineering and Management, 137(10), pp. 853-862.

Kerzner, H., \& Kerzner, H. R. (2017). Project Management: A Systems Approach to Planning, Scheduling, and Controlling. John Wiley \& Sons, Hoboken, NJ.

Kim, C., Park, T., Lim, H., \& Kim, H. (2013). On-site construction management using mobile computing technology. Automation in Construction, 35, pp. 415-423.

Klopfer, E., Squire, K., \& Jenkins, H. (2002). Environmental detectives: PDAs as a window into a virtual simulated world. In: Paper presented at the Proceedings of the IEEE International Workshop on Wireless and Mobile Technologies in Education 2002, Tokushima, Japan, 30-30 August, 2002.

Knutt, E. (2017). Balfour Beatty and energy specialist Cape embrace VR safety training. Available at https://www. healthandsafetyatwork.com/training/balfour-beatty-capeembrace-virtual-reality.

Koch, C., Neges, M., König, M., \& Abramovici, M. (2014). Natural markers for augmented reality-based indoor navigation and facility maintenance. Automation in Construction, 48, pp. 18-30.

Kopp, S., Jung, B., Lessmann, N., \& Wachsmuth, I. (2003). Max-a multimodal assistant in virtual reality construction. $K I, 17(4)$, p. 11.

Kumaran, G. S., Santhi, K., \& Anand, P. (2007). Impact of augmented reality (AR) in civil engineering. Advanced Materials Research, 18-19, pp. 63-68.

Kwon, O.-S., Park, C.-S., \& Lim, C.-R. (2014). A defect management system for reinforced concrete work utilizing BIM, image-matching and augmented reality. Automation in Construction, 46, pp. 74-81.

Le, Q. T., Pedro, A., Lim, C., Park, H., Park, C., \& Kim, H. (2015a). A framework for using mobile based virtual reality and augmented reality for experiential construction safety education. International Journal of Engineering Education, 31(3), pp. 713-725.

Le, Q. T., Pedro, A., \& Park, C. S. (2015b). A social virtual reality based construction safety education system for experiential learning. Journal of Intelligent \& Robotic Systems, 79(3-4), pp. 487-506.

Lee, K. (2012). Augmented reality in education and training. TechTrends, 56(2), pp. 13-21.

Lee, J.-Y., Kwon, O.-S., Choi, J.-S., \& Park, C.-S. (2012). A study on construction defect management using augmented reality technology. In: Paper presented at the Information Science and Applications (ICISA), 2012 International Conference on, Suwon, Korea.

Li, R. Y. M. (2018). Virtual Reality and Construction Safety. An Economic Analysis on Automated Construction Safety. Springer, Singapore, pp. 117-136. 
Li, X., Yi, W., Chi, H.-L., Wang, X., \& Chan, A. P. (2018). A critical review of virtual and augmented reality (VR/AR) applications in construction safety. Automation in Construction, 86, pp. 150-162.

Lin, T.-J., Duh, H. B.-L., Li, N., Wang, H.-Y., \& Tsai, C.-C. (2013). An investigation of learners' collaborative knowledge construction performances and behavior patterns in an augmented reality simulation system. Computers \& Education, 68, pp. 314-321.

Loijens, L. W., Brohm, D., \& Domurath, N. (2017). What is augmented reality? In: Loijens, Leanne W. S. (ed.), Augmented Reality for Food Marketers and Consumers. Wageningen Academic Publishers, Wageningen, p. 356.

Meža, S., Turk, Ž., \& Dolenc, M. (2015). Measuring the potential of augmented reality in civil engineering. Advances in Engineering Software, 90, pp. 1-10.

Olsson, T., Kärkkäinen, T., Lagerstam, E., \& Ventä-Olkkonen, L. (2012). User evaluation of mobile augmented reality scenarios. Journal of Ambient Intelligence and Smart Environments, 4(1), pp. 29-47.

Omar, T., \& Nehdi, M. L. (2016). Data acquisition technologies for construction progress tracking. Automation in Construction, 70 , pp. 143-155.

Park, C.-S., \& Kim, H.-J. (2013). A framework for construction safety management and visualization system. Automation in Construction, 33, pp. 95-103.

Park, C.-S., Lee, D.-Y., Kwon, O.-S., \& Wang, X. (2013). A framework for proactive construction defect management using BIM, augmented reality and ontology-based data collection template. Automation in Construction, 33, pp. 61-71.

Park, C. S., Le, Q. T., Pedro, A., \& Lim, C. R. (2015). Interactive building anatomy modeling for experiential building construction education. Journal of Professional Issues in Engineering Education and Practice, 142(3), p. 04015019.

Pejoska, J., Bauters, M., Purma, J., \& Leinonen, T. (2016). Social augmented reality: Enhancing context-dependent communication and informal learning at work. British Journal of Educational Technology, 47(3), pp. 474-483.

Peters, C., Postlethwaite, D., \& Wallace, M. W. (2016). Systems and methods providing enhanced education and training in a virtual reality environment: Google Patents.

Rankohi, S., \& Waugh, L. (2013). Review and analysis of augmented reality literature for construction industry. Visualization in Engineering, 1(1), p. 9.

Reddy, S., Estrin, D., \& Srivastava, M. (2010). Recruitment framework for participatory sensing data collections. In: Paper presented at the International Conference on Pervasive Computing, Helsinki, Finland.

Rozenfeld, O., Sacks, R., Rosenfeld, Y., \& Baum, H. (2010). Construction job safety analysis. Safety Science, 48(4), pp. 491-498.

Rumane, A. R. (2016). Quality Management in Construction Projects. CRC Press, Boca Raton, FL.

Sacks, R., Whyte, J., Swissa, D., Raviv, G., Zhou, W., \& Shapira, A. (2015). Safety by design: Dialogues between designers and builders using virtual reality. Construction Management and Economics, 33(1), pp. 55-72.

Sampaio, A. Z., Ferreira, M. M., Rosário, D. P., \& Martins, O. P. (2010). 3D and VR models in Civil Engineering education: Construction, rehabilitation and maintenance. Automation in Construction, 19(7), pp. 819-828.
Sampaio, A. Z., \& Martins, O. P. (2014). The application of virtual reality technology in the construction of bridge: The cantilever and incremental launching methods. Automation in Construction, 37, pp. 58-67.

Science. (Producer). (2017, 21 April 2018). 3M Virtual Reality Simulation Adds New Dimension to Safety Training. Available at https://www.youtube.com/watch?v=yhR-_TY6j50.

Sekizuka, R., Koiwai, K., Saiki, S., Yamazaki, Y., Tsuji, T., \& Kurita, Y. (2017). A virtual training system of a hydraulic excavator using a remote controlled excavator with augmented reality. In: Paper presented at the Proceedings of the 2017 IEEE/SICE International Symposium on System Integration (SII), Taipei, Taiwan, 11-14 December, 2017.

Shen, W., Hao, Q., Mak, H., Neelamkavil, J., Xie, H., Dickinson, J., et al. (2010). Systems integration and collaboration in architecture, engineering, construction, and facilities management: A review. Advanced Engineering Informatics, 24(2), pp. 196-207.

Sidani, A. Z., Duarte, J., Dinis, F. M., Baptista, J. S., Martins, J. P., \& Soeiro, A. (2018). The Impact of BIM-based virtual and augmented reality interfaces on health and safety in construction projects: Protocol for a systematic review. International Journal of Occupational and Environmental Safety, 2(1), pp. 67-74.

Stricker, D., Klinker, G., \& Reiners, D. (2001). Augmented reality for exterior construction applications. In: Barfield, W., \& Caudell, T. (eds.), Fundamentals of Wearable Computers and Augmented Reality. Lawrence Erlbaum Associates Publishers, Mahwah, NJ, pp. 379-427.

Tang, A., Owen, C., Biocca, F., \& Mou, W. (2003). Comparative effectiveness of augmented reality in object assembly. In: Paper presented at the Proceedings of the SIGCHI Conference on Human Factors in Computing Systems, Ft. Lauderdale, Florida, USA: ACM.

Turkan, Y., Bosche, F., Haas, C. T., \& Haas, R. (2012). Automated progress tracking using $4 \mathrm{D}$ schedule and $3 \mathrm{D}$ sensing technologies. Automation in Construction, 22, pp. 414-421.

Van Krevelen, D., \& Poelman, R. (2010). A survey of augmented reality technologies, applications and limitations. International Journal of Virtual Reality, 9(2), p. 1.

Wang, X. (2009). Augmented reality in architecture and design: Potentials and challenges for application. International Journal of Architectural Computing, 7(2), pp. 309-326.

Wang, X., \& Dunston, P. S. (2007). Design, strategies, and issues towards an augmented reality-based construction training platform. Journal of Information Technology in Construction (ITcon), 12(25), pp. 363-380.

Wang, X., Love, P. E., Kim, M. J., Park, C.-S., Sing, C.-P., \& Hou, L. (2013). A conceptual framework for integrating building information modeling with augmented reality. Automation in Construction, 34, pp. 37-44.

Wang, W.-C., Weng, S.-W., Wang, S.-H., \& Chen, C.-Y. (2014a). Integrating building information models with construction process simulations for project scheduling support. Automation in Construction, 37, pp. 68-80.

Wang, X., Truijens, M., Hou, L., Wang, Y., \& Zhou, Y. (2014b). Integrating augmented reality with building information modeling: Onsite construction process controlling for liquefied natural gas industry. Automation in Construction, 40, pp. 96-105. 
Whyte, J. (2003a). Industrial applications of virtual reality in architecture and construction. Journal of Information Technology in Construction (ITcon), 8(4), pp. 43-50.

Whyte, J. (2003b). Innovation and users: Virtual reality in the construction sector. Construction Management and Economics, 21(6), pp. 565-572.

Williams, G., Gheisari, M., Chen, P.-J., \& Irizarry, J. (2014). BIM2MAR: An efficient BIM translation to mobile augmented reality applications. Journal of Management in Engineering, 31(1), p. A4014009.

Wong, J., Wang, X., Li, H., \& Chan, G. (2014). A review of cloud-based BIM technology in the construction sector. Journal of Information Technology in Construction, 19, pp. 281-291.

Woodward, C., Hakkarainen, M., Korkalo, O., Kantonen, T., Aittala, M., Rainio, K., et al. (2010). Mixed reality for mobile construction site visualization and communication. In: Paper presented at the Proceedings of 10th International Conference on Construction Applications of Virtual Reality (CONVR2010), Sendai, Japan, 4-5 November, 2010.

Yeh, K.-C., Tsai, M.-H., \& Kang, S.-C. (2012). On-site building information retrieval by using projection-based augmented reality. Journal of Computing in Civil Engineering, 26(3), pp. 342-355.

Zaher, M., Greenwood, D., \& Marzouk, M. (2018). Mobile augmented reality applications for construction projects. Construction Innovation, 18(2), pp. 152-166.

Zhao, D., \& Lucas, J. (2015). Virtual reality simulation for construction safety promotion. International Journal of Injury Control and Safety Promotion, 22(1), pp. 57-67.

Zhou, F., Duh, H. B.-L., \& Billinghurst, M. (2008). Trends in augmented reality tracking, interaction and display: A review of ten years of ISMAR. In: Paper presented at the Proceedings of the 7th IEEE/ACM International Symposium on Mixed and Augmented Reality, Washington, DC, USA: IEEE Computer Society, 2008. 